Oriente e Ocidente 



\section{Sobre a universidade ${ }^{1}$}

Edward W. Saïd

Magnífico Reitor, Senador Hatfield, membros do Conselho de Curadores da $A U C^{2}$, membros da faculdade AUC e pessoal administrativo, membros da classe dos formandos, ilustres convidados, pais, parentes e amigos, senhoras e senhores:

Não me importo em lhes confessar, como um sinal de minha idade quase bíblica, que há cinquenta anos, durante os anos 1940, cresci no Cairo e que a Universidade Americana do Cairo foi a primeira universidade com a qual tive algum contato. Dois de meus primos de Jerusalém estudaram aqui, meu pai era amigo próximo de John Badeau, então reitor desta universidade, e, posteriormente, embaixador de John Kennedy no Egito; por fim, a Sala Ewart era a principal sala de concertos do Cairo, e foi lá que adquiri os rudimentos da minha formação musical. Aos poucos tomei consciência de suas equivalentes locais, a Universidade do Cairo e a Universidade de al-Azhar, cada qual, como a AUC, prestando um valioso serviço a gerações de estudantes egípcios, árabes e muçulmanos. Eu também tenho orgulho em dizer que, em 1994, meu filho Wadie aperfeiçoou seu extraordinário domínio da língua árabe aqui mesmo, no Centro de Estudos Árabes no Exterior (CASA), um grande feito para um garoto de Nova lorque que, por uma questão de solidariedade com sua origem árabe, se tornou fluente na língua e na cultura de seus antepassados em uma época em que tanto uma quanto outra eram vistas com hostilidade nos

1 Este artigo foi primeiramente publicado como: SAÏD, Edward W. On the University. Alif: Journal of Comparative Poetics, n. 25, p. 26-36, 2005. Tradução para o português de Everson Machado. Publicação autorizada. Agradecemos ao Professor Walid El Hamamsy, editor Chefe da revista Alif, a autorização para a publicação em português.

2 Universidade Americana do Cairo. 
Estados Unidos, terra em que nasceu e foi criado. Estou honrado e feliz por estar aqui hoje, em primeiro lugar, enquanto árabe palestino e filho da imensa e inigualável história cultural do Egito e, em segundo lugar, enquanto americano. A combinação dessas duas diferentes correntes na AUC - e, claro, em vocês mesmos, turma de 1999, a última do século - é extremamente desafiadora e enriquecedora, mas, ao mesmo tempo, muito problemática. Qualquer um que conheça a sociedade americana e a sociedade egípcia sabe das diferenças existentes entre elas, então, não vou me deter no que é óbvio. 0 que é importante observar é o fato de que em instituições como a $A U C$, e na sua equivalente, $A U^{3}$, a ideia de uma educação liberal secular, que, nos séculos $X I X$ e $X X$, teve por precursoras as grandes universidades americanas, foi implantada com resultados bastante positivos em sociedades árabes, de maioria muçulmana, e, em termos de mera longevidade, extremamente antigas, em processo de renovação e libertação após longos períodos sob domínio externo.

Quaisquer que sejam os resultados dessa mistura ousada certamente não serão nem simples nem previsíveis. Cada um dos senhores, tanto estudantes quanto professores, deve ter sua própria avaliação com base em seus anos de interação com ideias vertiginosamente diferentes, experiências pessoais diversas, expectativas, frustrações e realizações, mas não posso imaginar que alguém diria que os resultados foram nada menos que interessantes, ricos e, sim, perturbadores. A razão principal, no entanto, é que essa experiência coletiva, variada, aconteceu em um local muito especial, a saber, a universidade. Enquanto alguém que passou a maior parte de sua vida adulta trabalhando na universidade e pela universidade, deixem-me repetir-lhes o que uma vez um de meus professores me disse: é muito mais divertido que trabalhar. Muitos de vocês, graduados com empregos de verdade no mundo real, descobrirão isso.

Não é essa a minha questão central, e sim que em toda sociedade conhecida - do antigo Oriente Médio, do mundo árabe, da China, Índia, Grécia, e por aí afora -, a academia, como Platão a nomeou, foi um lugar protegido, quase utópico. Apenas nela o aprendizado coletivo e

3 Universidade Americana de Beirute. 
o desenvolvimento do conhecimento acontecem e, como se descobriu recentemente, apenas poderia acontecer se a liberdade acadêmica estivesse de alguma forma protegida e pudesse resistir à autoridade não acadêmica. Foi extraordinário descobrir, por meio do notável livro de George Makdisi, The Rise of Humanism in Classical Islam and the Christian West [0 surgimento do Humanismo no Islã clássico e o cristianismo ocidental], que o sistema moderno de conhecimento a que chamamos de Humanismo não teve origem, como Jakob Burckhardt e tantos outros acreditaram, na Itália, durante o Renascimento nos séculos XV e XVI, mas sim antes, nas universidades árabes, madrasas, mesquitas e cortes do Iraque, da Sicília, do Egito, da Andaluzia, a partir do século VIII. Nesses lugares, formaram-se tradições e currículos de estudos legais, teológicos e seculares - conhecidos como studia adabiya -, a partir dos quais os humanistas europeus, como Pico della Mirandola, Ficino, Aretino e Thomas Morus derivaram muitas de suas ideias, não apenas sobre o próprio saber, mas também sobre o ambiente do saber, em que disputa, divergência e argumentação estavam na ordem do dia.

Para aqueles dentre nós de origem árabe, e que nos dias de hoje se acostumaram à ideia de que a Europa e o Ocidente deram origem aos modos de estudo, às noções de disciplina acadêmica e à própria ideia do que em árabe chamamos de ijtihad, ou o papel central do esforço individual no estudo e na interpretação, é salutar, de fato, perceber que nossa cultura árabo-islâmica contribuiu substancialmente para o que viria a se tornar o sistema educacional que hoje chamamos de moderno, liberal e ocidental. Não tenho muita paciência com o tipo de etnocentrismo alardeado por Samuel Huntington e assemelhados que vivem repetindo que as ideias de democracia, liberdade e iluminismo são ocidentais, pois, quando se trata de educação, os fatos históricos são muito variados, muito confusos e, principalmente, uma questão das contribuições feitas por toda a humanidade, por todos os povos, por todas as culturas. Não há uma única fonte de tudo: todos os povos partilham a feitura da história, todos os povos fazem história. Convenhamos, então, que se olharmos para o período de Ibn 'Abbad ou Ibn 'Arabi, ou para o de John Dewey, no século $\mathrm{XX}$, encontraremos pensadores sérios sugerindo mais ou menos a mesma coisa, isto é, que o lugar da educação é um território especial no interior da sociedade, um lugar em que a liberdade de pesquisa e de 
pensamento acontece e é protegido e em que - é preciso ser dito - os contextos social e político têm um papel importante ao definir os limites e as expectativas do processo de aprendizado. A Universidade Americana no Cairo está no Cairo, portanto, não em Nova lorque ou em Londres. Isso é óbvio. Cairo é um ambiente específico com suas próprias histórias, leis, língua e normas. Não levar em conta isso tudo é evidentemente errado.

E, no entanto, o status da universidade ou da escola, assim como tudo o que as acompanha intelectual e socialmente, é especial, é diferente de outros espaços na sociedade, como a burocracia governamental, o local de trabalho ou o lar. O fato é, creio eu, que todas as sociedades hoje em dia atribuem um privilégio especial à academia, seja ao isentá-la da relação com o mundo cotidiano, seja ao implicá-la diretamente nesse mundo, e esta diz que condições únicas prevalecem ou de fato devem nela prevalecer. Dizer que alguém é educado, ou um educador, é dizer algo que tem a ver com a mente, com valores morais e intelectuais, com processos específicos de pesquisa, discussão e troca, nenhum dos quais é encontrado tão comumente fora da academia como o é dentro dela. A ideia é que a academia forma a mente dos jovens, prepara-os para a vida, assim como - para tomar a perspectiva do professor - ensinar é seguir uma vocação que se relaciona, principalmente, não com o ganho financeiro, mas com a busca infınita da verdade.

Essas são questões de suma importância e que, para aqueles dentre nós que fizemos da educação nossa vida, atestam a verdadeira aura que cerca a atividade intelectual e acadêmica. Há algo de venerável e sagrado na academia: há uma espécie de sentimento de profanação que experimentamos quando a universidade ou a escola é submetida a pressões políticas grosseiras. E, no entanto, acredito que estar convencido dessas verdades realmente poderosas não significa estar livre das circunstâncias - alguns as chamariam de estorvos - que constrangem atualmente a educação, influenciam a forma como pensamos a seu respeito e moldam nossos esforços na academia. 0 que eu gostaria de enfatizar é que, enquanto refletimos sobre essas questões contextuais ou situacionais, a busca por liberdade acadêmica - e ocasiões como esta servem a este objetivo - torna-se mais importante, mais urgente e requer uma análise mais cuidadosa e reflexiva. Assim, enquanto se pode dizer que é universalmente verdadeiro que as sociedades contemporâneas tratam 
a academia com seriedade e respeito, cada comunidade de acadêmicos, intelectuais e estudantes deve lidar com o problema do que é realmente a liberdade acadêmica nessa sociedade e nesse tempo específicos e como ela deveria ser.

A melhor definição de uma universidade que eu conheço foi dada por John Henry Cardinal Newman, que, em 1854, foi da Inglaterra para a Irlanda para criar o que se tornou a Universidade Nacional da Irlanda, Dublin (University College, Dublin). Eis o que disse na ocasião:

A universidade tem esse objeto e essa missão; não contempla impressões morais nem produção mecânica; professa exercitar a mente, não na arte nem no dever; sua função é cultura intelectual; assim pode ir além de seus especialistas e faz seu trabalho quando se limita a fazer isso. A universidade educa o intelecto a bem raciocinar em todas as matérias, a buscar alcançar a verdade e a apreendê-la.

Talvez vocês, recém-graduados, não sintam que tiveram essa experiência ou, talvez ainda, acreditem que já que estão formados, não precisam mais se preocupar com a universidade, exceto como alumni. Isso seria um erro. Vocês não são apenas formados e ex-estudantes, mas cidadãos, e cidadania demanda uma firme atenção para as questões que são vitais para a sociedade. E, certamente, não há nada mais vital no longo prazo para o Egito que a educação e a vida da mente, especialmente aqui, em nossa parte do mundo, onde, infelizmente, estamos atrasados em se tratando de democracia, liberdades de expressão, opinião e a impressa, e a plena participação em sociedades há muito dominadas por preocupações com a segurança nacional e não com a saúde cívica e intelectual do povo. Desse modo, a liberdade da universidade é uma preocupação permanente e demanda sua atenção assim como seu apoio contínuo.

Mas voltemos a Newman. Observem o cuidado com que ele escolhe as palavras para descrever as ações que ocorrem na busca pelo conhecimento: exercitar, educar, alcançar e apreender. Nenhuma delas sugere coerção, utilidade, vantagem imediata ou domínio. "Conhecimento", Newman diz em outro lugar, é "algo intelectual, algo que apreende o que percebe através dos sentidos, algo que capta uma visão das coisas, que vê mais do que os sentidos transmitem, que raciocina sobre o que vê e enquanto vê, que reveste isso com uma ideia". E, então, acrescenta: "não 
saber a disposição relativa das coisas é a condição de escravos e crianças; ter mapeado o universo é motivo de orgulho para a filosofia ou, ao menos, essa é sua ambição", o que Newman define como o estado mais elevado do conhecimento.

Essas declarações, de eloquência incomparável, podem ser um pouco relativizadas apenas quando nos lembramos de que Newman falava de homens ingleses para homens ingleses, e não para mulheres, e a respeito da educação de jovens católicos, e não de árabes ou egípcios. Apesar disso, a verdade profunda daquilo que Newman diz, creio eu, visa minar qualquer visão estreita ou parcial da educação cuja fınalidade seria reafirmar uma identidade dominante e particularmente atraente, a religião e a autoridade que é o poder local ou a autoridade do momento. Talvez como muitos de seus contemporâneos vitorianos, Newman argumentasse sinceramente em defesa de um tipo de educação em que prevaleceriam os valores cristãos, europeus e ingleses no conhecimento. Mas, às vezes, embora queiramos dizer algo, outro pensamento em desacordo com o que dizemos se insinua em nossa retórica, critica-o, resultando em uma ideia diferente e menos assertiva do aquilo que na superfície poderíamos ter pretendido. Isso acontece quando lemos Newman. De repente, percebemos que, embora ele obviamente esteja exaltando o que é primordialmente uma concepção ocidental do mundo sem levar explicitamente em conta o que é africano, árabe, latino-americano ou indiano, percebemos que ele diz que a educação deveria mapear o universo, deixando, assim, escapar a ideia de que a identidade inglesa ou mesmo europeia não seria suficiente, não seria o fundamento ou, na melhor das hipóteses, não seria aquilo que diz respeito à educação e à liberdade, que é "o universo".

Por certo é difícil encontrar em Newman algo como uma licença seja para uma especialização míope, seja para um esteticismo de gentilhomem. O que espera da academia, diz ele, é "o poder de ver muitas coisas de uma só vez como um todo, de reenviá-las individualmente ao seu verdadeiro lugar no sistema universal, de entender seus respectivos valores e de determinar sua dependência mútua". Essa totalidade sintética tem uma relevância especial para as situações políticas de conflito difíceis, para a tensão não resolvida, assim como as disparidades morais e sociais que são constitutivas do mundo acadêmico de hoje em dia. Ele propõe uma ampla e generosa visão da diversidade humana. Estabelecer uma 
relação direta entre a prática da educação e, por extensão, da liberdade na academia com um acerto de contas político ou com uma reflexão igualmente desregrada a respeito de um conflito nacional e religioso real não é nem propriamente buscar o conhecimento nem, por fim, nos educarmos a nós mesmos ou educarmos nossos estudantes, o que é um eterno esforço de compreensão. Mas o que acontece quando tomamos as prescrições de Newman sobre ver muitas coisas como um todo ou reenviá-las ao seu verdadeiro lugar no sistema universal e transpomos essas noções para o mundo atual de identidades nacionais em confronto, conflitos culturais e relações de poder? Há alguma possibilidade de preencher o fosso entre a torre de marfım da racionalidade contemplativa, ostensivamente advogada por Newman, e nossa própria necessidade urgente, enquanto árabes com uma história de repressão e denegação, de autoafirmação e autorrealização? Pode a universidade sobreviver como uma verdadeira universidade se sua governança e missão de ensinar se tornam objeto de escrutínio e de interferência direta, não de professores, mas de poderes externos à universidade?

Penso que não e direi mais: penso que é precisamente o papel da academia contemporânea manter aberto o fosso que a separa da sociedade, uma vez que a própria sociedade é governada pela política de forma muito imediata para desempenhar um papel tão geral e, enfim, intelectual e moral como a universidade nitidamente deve fazer. Precisamos, em primeiro lugar, aceitar que nacionalismo ou religião renascente, ou mesmo nacionalismo e religião militante, seja ele nacionalismo da vítima ou do vencedor, que tal nacionalismo tem seus limites. Nacionalismo e religião são a filosofia da identidade transformada em uma paixão organizada coletivamente. Para aqueles entre nós que apenas emergimos da marginalidade e da perseguição, nossas tradições constituem algo necessário: uma identidade negada e adiada por tanto tempo precisa se expor em campo aberto e tomar seu lugar entre as outras identidades humanas. Mas este é apenas o primeiro passo. Tornar toda a educação, ou sua maior parte, subserviente a esse fim é rebaixar o horizonte humano, sem qualquer garantia intelectual ou política, eu diria. Assumir que os fins da educação são mais bem promovidos ao convergirem principalmente para a nossa própria singularidade, ou com o que concorda com nossa própria identidade étnica, cultura e tradições, 
ironicamente nos coloca no mesmo lugar que fôramos postos pela teoria racial do século XIX, enquanto raças inferiores ou menores, incapazes de partilhar da riqueza geral da cultura humana. 0 que significa que as mulheres deveriam ler basicamente literatura feminina aprovada; que muçulmanos deveriam estudar e aperfeiçoar apenas técnicas muçulmanas de compreensão e interpretação; que os árabes deveriam retornar a um conjunto de obras aceitáveis para todo conhecimento e sabedoria e deveriam ler na universidade apenas o que é considerado seguro e ortodoxo. Isto é, de fato, ficarmos presos ao passado, sermos impedidos de participar da marcha da humanidade. Há espaço para todos no encontro marcado com a vitória, disse Aimé Césaire. Nenhuma raça tem o monopólio da beleza ou da inteligência.

Uma única identidade predominante - ocidental, africana, islâmica, asiática - e guiada por uma autoridade religiosa ou secular de fora da universidade no coração da atividade acadêmica significa um confinamento, uma privação. 0 mundo em que vivemos é composto de inúmeras identidades, inúmeras ideias, vidas, filosofias, interagindo às vezes de forma harmônica, às vezes antiteticamente. Não lidar com essa totalidade - que é, de fato, uma versão contemporânea do todo mencionado por Newman como a verdadeira ampliação da mente significa não ter liberdade acadêmica. Não podemos afirmar que somos aqueles que buscam a justiça se advogarmos um conhecimento apenas de nós mesmos e sobre nós mesmos, conhecimento este que é aprovado por uma equipe de juízes que decide o que pode e o que não pode ser lido. Quem então julgará os juízes? Assim, uma das inovações de uma Universidade Americana no Egito está precisamente no fato de encorajar seus estudantes a experimentar não apenas suas culturas e tradições, mas também outras. Isso, creio eu, é profundamente enriquecedor, talvez perturbador, e o exato oposto de um aprendizado homogeneizante de apenas uma única forma aprovada. Mas esta tem sido desafiada e é preciso resistir às tentativas de banir livros e proibir ideias.

Nosso modelo para a liberdade acadêmica deveria ser, portanto, o migrante ou o viajante. Se no mundo real, exterior à academia, precisamos ser nós mesmos e apenas nós mesmos, no interior da academia, como esta aqui, deveríamos ser capazes de descobrir e viajar entre outros Eus, outras identidades, outras variantes da aventura humana. Mas o que é o 
mais importante nessa descoberta conjunta do eu e do outro é o papel da academia de transformar o que poderia tornar-se ou conflito, ou contenda, ou asseveração em reconciliação, reciprocidade, reconhecimento, interação criativa. Ao invés de considerar a busca pelo conhecimento na academia como a busca por coerção e controle sobre os demais, deveríamos ver o conhecimento como algo que, para ser alcançado, nos obriga a correr riscos, e deveríamos pensar a liberdade acadêmica como um convite para explorar o conhecimento na esperança de compreensão, talvez assumindo mais de uma. Devemos sempre ver a academia como um lugar em que se viaja, nada possuindo dela, mas onde se está em casa em toda parte. Não pode haver um conhecimento proibido se a universidade moderna quiser manter seu lugar, sua missão, seu poder de educar.

Um desafio ao conceito de liberdade acadêmica inteiramente diferente existe nas universidades nacionais de grande parte do mundo árabe contemporâneo. Eu me refiro, de modo geral, à maioria das grandes universidades públicas nos países da região. A maior parte desses países é, de fato, dirigida por governos seculares. 0 que é importante entender, no entanto, é que, com algumas poucas exceções, as universidades árabes não são apenas universidades nacionalistas, mas também instituições políticas - e por razões absolutamente compreeensíveis. Na Palestina, por exemplo, Bir Zeit e al-Najah têm resistido à ocupação israelense e preservaram a identidade palestina de um modo admirável. Em outras partes, o mundo árabe, outrora dominado pelo Império Otomano, seja pelo colonialismo europeu, tornou-se independente após a Segunda Guerra Mundial. A independência nacional de países como o Egito e a Síria significou para os jovens a possibilidade de serem, enfim, educados inteiramente nas tradições, histórias, línguas e cultura de seus países árabes de origem. No meu caso, por exemplo, toda a minha educação foi feita exclusivamente em escolas coloniais britânicas na Palestina e no Egito, e nessas escolas tudo convergia para a história da sociedade britânica, sua literatura e seus valores. 0 mesmo acontece nas principais colônias britânicas e francesas, tais como Índia e Argélia, em que se supunha que às elites nativas seriam ensinadas as noções básicas da cultura intelectual, em idiomas e métodos cujo objetivo, de fato, era manter essas elites nativas basicamente subservientes ao domínio colonial, à superioridade do saber europeu, e assim por diante. Até os 16 anos, eu 
sabia muito mais sobre o sistema de cercamentos do século XVIII na Inglaterra do que sobre como o waqf islâmico operava em minha própria parte do mundo e, para mim - ironia das ironias -, procônsules coloniais, como Cromer e Kitchener, eram mais familiares que Haroun al-Rashid ou Khalid ibn al-Walid.

Desse modo, quando foi alcançada a independência, como resultado das lutas anticoloniais, uma das primeiras coisas a ser mudada foi a educação. Lembro-me, por exemplo, de que após a Revolução de 1952, no Egito, muita ênfase foi colocada na arabização do currículo, das normas intelectuais, dos valores a serem inculcados nas escolas e universidades. O mesmo aconteceu com a Argélia depois de 1962, quando uma geração inteira de muçulmanos teve, pela primeira vez, o direito de estudar o árabe e foi encorajada a isso. A língua era proibida e falada apenas nas mesquitas no período em que a Argélia era considerada e governada como um departamento da França. É importante, assim, entender a paixão com que se reclamou o território educacional, que por tanto tempo foi dominado por governantes estrangeiros no mundo árabe, e é igualmente importante entender a tremenda ferida espiritual que muitos de nós sentimos por causa da presença contínua, em nosso meio, de estrangeiros que nos dominavam e nos ensinaram a respeitar as normas e os valores deles mais do que os nossos. Nossa cultura era considerada de nível inferior, talvez até naturalmente inferior, e algo para se envergonhar.

Mas seria errado, e absurdo, sugerir que uma educação nacional baseada em normas árabes seja por si só superficial ou empobrecida. É claro que não. No entanto, também é verdade que, nos países recémindependentes do mundo árabe, as universidades nacionais foram muitas vezes reformuladas como extensões (correta ou incorretamente) do recém-estabelecido Estado de segurança nacional. Mais uma vez, é claro que todas as sociedades concedem um privilégio excepcional à universidade e à escola, como cadinhos para a formação da identidade nacional. Isso é verdade em todos os lugares, às vezes a um preço muito alto. Nos EUA, houve muita pressão sobre as universidades para beneficiar o departamento de defesa, especialmente durante a Guerra Fria e a Guerra do Vietnã.

No entanto, e com frequência no mundo árabe, a verdadeira educação sofreu um curto-circuito, por assim dizer. Enquanto no passado os jovens 
árabes eram vítimas da intervenção de ideias e normas estrangeiras, agora eles deveriam ser refeitos à imagem do partido no poder, que, por causa da Guerra Fria e da luta árabe-israelense, se tornou também o partido da segurança nacional e, em alguns países, o único partido. Assim, aumentando a pressão sobre as universidades para abrir suas portas a todos na nova sociedade - uma política muito admirável, iniciada no Egito -, as universidades também se tornaram o campo de testes para os patriotas convictos. Isso também aconteceu durante o período McCarthy nos EUA, quando qualquer um que fosse suspeito de defender ideias de esquerda era perseguido. As nomeações para professores eram, como em muitos lugares do mundo de hoje, o equivalente às nomeações para o serviço público. No entanto, infelizmente, em vez da excelência intelectual, a conformidade política costumava servir como critério de nomeação e promoção, tendo por resultado geral que a timidez, uma estudiosa falta de imaginação e um cuidadoso conservadorismo vieram dominar a prática intelectual. Isso é um perigo em todos os lugares, nos EUA, na Europa, no Terceiro Mundo etc. Muitas vezes, a atmosfera da universidade mudou de liberdade para acomodação, de brilho e ousadia para cautela e medo, do avanço do conhecimento para a autopreservação.

Muitas pessoas inteligentes e talentosas deixaram o mundo árabe em uma grande evasão de cérebros e eu diria que toda a noção de liberdade acadêmica sofreu uma significativa degradação nas últimas três décadas. Ser livre na universidade se tornou possível apenas sob a condição de evitar atrair atenção indesejada ou qualquer suspeita sobre si mesmo. Não quero fazer desta ocasião uma lamúria de quão deprimente e desanimador o mundo árabe se tornou, na maioria de seus aspectos contemporâneos, mas acho que é importante vincular sua situação melancólica à falta de direitos democráticos, à ausência de imprensa livre e à atmosfera desprovida de bem-estar e confiança na sociedade. Ninguém pode dizer que essas coisas não estão conectadas entre si, porque obviamente estão. A repressão política nunca foi boa para a liberdade acadêmica e, talvez mais importante, foi desastrosa para a excelência acadêmica e intelectual em razão de práticas como proibição de livros e censura. Minha avaliação, repito, é que um preço muito alto foi pago onde se permitiu que paixões políticas ou religiosas, assim como uma ideologia da conformidade, dominassem e até engolissem instituições civis, como 
a universidade. Tornar a prática do discurso intelectual dependente da conformidade com uma ideologia política ou religiosa predeterminada é anular completamente o intelecto. Por fim, chegamos a duas imagens que habitam o espaço acadêmico e cultural fornecido pela universidade. De um lado, existe a autoridade para reinar e dominar. Aqui, nessa concepção de espaço acadêmico, o profissional acadêmico e a autoridade pública são o sultão e o potentado. Nesse modelo, os alunos são ensinados a não questionar, a seguir a autoridade, a não ser cético - isto é, a continuar pesquisando -, mas a se apegar ao dogma. De outro lado, o modelo é consideravelmente mais móvel, mais divertido, embora não menos sério. A imagem do viajante depende não do poder, mas do movimento, da vontade de entrar em mundos diferentes, de usar diferentes línguas, de entender uma variedade de disfarces, máscaras, retóricas e de ser livre para fazê-lo, e de ser crítico, e de pensar por si mesmo. Os viajantes devem suspender a pretensão à rotina habitual, a fim de viverem em novos ritmos e rituais. Acima de tudo antípoda do sultão, que deve guardar apenas um lugar e defender suas fronteiras, o viajante atravessa, cruza territórios, abandona posições fixas o tempo todo. Fazer isso com dedicação e amor, bem como uma ter percepção realista do terreno, é, creio, o ápice da liberdade acadêmica, pois uma de suas principais características é que você pode deixar a autoridade e o dogma para o sultão. Liberdade acadêmica é risco e perigo. Significa permitirem-se alguns anos em que as convenções da sociedade estão suspensas para que a busca pelo conhecimento possa continuar apenas pelo amor ao conhecimento. Ser um membro vitalício do mundo acadêmico, como vocês, recém-formados e professores, é entrar em uma busca incessante por princípios e conhecimentos, libertação e, finalmente, por justiça. 